\title{
COMPARISON OF THE ECHOLOCATION BEHAVIOR IN RHINOLOPHUS FERRUM-EQUINUM AND CHILONYCTERIS RUBIGINOSA
}

\author{
by \\ HANS-ULRICH SCHNITZLER \\ Zoophysiologisches Institut der Universität Tübingen, B.R. Deutschland \\ and \\ Rockefeller University and Institute for Research in Animal Behavior, New York, U.S.A.
}

The results of Novick (1958), Griffin (1962), Kay \& Pickvance (1963), A. Pye (1966), Schnitzler (1967, 1968), Ajrapetjanz \& Konstantinov (1967), and Konstantinov \& Sokolov (1969) show that Rhinolophus ferrum-equinum Schreber, 1774 (RF) produces long pulses of constant frequency with a slight upward sweep at the start and a downward sweep at the end. These are similar to the sounds of Chilonycteris rubiginosa fusca J. A. Allen, 1911 (CR) described by Griffin \& Novick (1955), Novick (1963a), Novick \& Vaisnys (1964), A. Pye (1967), and Schnitzler (1970). Therefore it is interesting to compare the sound emission of both species in a similar orientation situation, while flying from a starting place across a room to a landing bar. The flight distance was $6.5 \mathrm{~m}$ in RF and $2.4 \mathrm{~m}$ in CR. The experiments with RF were done at the Zoophysiologisches Institut in Tübingen and with CR at the Rockefeller University and the Institute for Research in Animal Behavior in New York.

\section{RESULTS}

RF emits the sounds through the nostrils and CR through the open mouth. The horseschoe-shaped noseleaves surrounding the nostrils in RF and the widely opened lips in CR form a megaphonlike structure and may function as a beaming device (Möhres, 1953; Novick, 1963a).

Both species emit tripartite sounds in all orientation situations. In the beginning part the frequency rises by $1-9 \mathrm{kHz}$ in $\mathrm{RF}$ and $1-2 \mathrm{kHz}$ in CR. The middle part has a constant frequency and comprises at least $9 / 10$ of the entire pulse in $\mathrm{RF}$ and $4 / 5$ in CR. The main intensity in both species is in the second harmonic at a frequency of about $83 \mathrm{kHz}$ in RF and $57 \mathrm{kHz}$ in CR. The terminal part is frequency modulated. The fre- quency drops by $13-16 \mathrm{kHz}$ in $\mathrm{RF}$ and about 8 $\mathrm{kHz}$ in $\mathrm{CR}$.

In a mixture of $80 \%$ helium and $20 \%$ oxygen both species produce pulses which show only the first and the third harmonic. These experiments suggest that the laryngeal membranes of these bats vibrate at a low ultrasonic frequency and that cavity resonances in the respiratory tract accentuate the second harmonic and suppress the fundamental and higher harmonics. In the $\mathrm{He} / \mathrm{O}_{2}$ mixture the sound velocity and consequently the cavity resonance are different; therefore the second harmonic is filtered out and other harmonics can pass.

Before taking off RF emits single pulses of 55$65 \mathrm{msec}$ duration. If the bat's attention is drawn to an object, the bat produces groups of 2-8 shorter pulses. The repetition rate of either single sounds or groups is about 4-7 per second. A comparison with the respiration rate shows that RF emits either a single sound or a group of sounds within each respiratory cycle. Roosting CR generally produce per group 2 pulses of $20-27 \mathrm{msec}$ duration. The arrangement in groups is not so clear as in RF since the interval between the pulses within a group is longer. Shortly before taking off CR emitted a group with 4-6 pulses lasting $14-20 \mathrm{msec}$. However in these experiments CR was stimulated to take off by touching whereas RF started to fly of their own accord.

The flight of both species can be divided in three behavioral categories: free flight or search flight, approach phase and terminal phase (Griffin, Webster \& Michael, 1960). In free flight the bats do not show a special interest for a goal or obstacle. In a natural situation they would be searching for insects. It is difficult to realize this situation in the laboratory and perhaps the results are influenced 
by the room size. Free flying RF produce 10-12 single pulses of 50-65 msec duration, probably one per respiratory cycle. CR emit per second 10-11 groups of 2 pulses lasting 17-23 msec. Since in the experiment with CR the flight space was only 60 $\mathrm{cm}$ wide, it might be that in a natural situation they would emit single sounds as do RF. A comparison of the sound emission with the movement of the wings shows that both species produce either one single sound or a group of sound per wingbeat. The first sound of a group is always emitted when the wing is raised.

The approach phase starts with the beginning of the landing manoeuver. It is characterized in both species by groups with an increasing number of sounds of decreasing duration. In the terminal phase beginning shortly before hanging up, the bats produce a long group with many short sounds. In RF this group comprises about 20 pulses with a minimum duration of $10 \mathrm{msec}$. In CR three bats had 20-30 pulses in the terminal group with a minimum duration of $4 \mathrm{msec}$, whereas one bat always produced only 9-10 pulses in the terminal group. The maximum pulse repetition rate rises to 70-80 per sec in RF and about 125 in CR. With decreasing sound duration the duration of the frequencymodulated $(\mathrm{fm})$ part is diminished.

In both species the sonagrams of pulses of the approach and terminal phase sometimes showed an additional 1st and 3rd harmonic whereas the pulses in free flight and at roosting only showed the 2nd harmonic.

Roosting RF and CR maintain the frequency of the part with constant frequency (cf) within about $\pm 100 \mathrm{~Hz}$ of the average frequency. In flight both species lower the frequency of the cfpart in order to compensate for Doppler shifts caused by the flight velocity. The frequency heard by the bats is, thus, maintained within a ca. 200 $\mathrm{Hz}$ wide frequency band whose center frequency is about $100-150 \mathrm{~Hz}$ above the average frequency emitted before flight. RF therefore lowers the frequency of the cf-parts of the emitted sounds at a flight velocity of $4.8 \mathrm{~m} / \mathrm{sec}$ for about $2.3 \mathrm{kHz}$ and $\mathrm{CR}$ at $3 \mathrm{~m} / \mathrm{sec}$ for about $1 \mathrm{kHz}$. In flight both species are able to compensate for Doppler shifts caused by the flight velocity by lowering the emitted frequency in order to keep the echo frequency in a small frequency band. One RF roosting in front of a pendulum swinging toward and away from it even tried to compensate the Doppler shifts caused by the pendulum in order to keep the echo frequency constant.
RF and CR show ear movements. In RF these movements are alternating and closely correlated to sound emission (Schneider \& Möhres, 1960; Griffin, Dunning, Cahlander \& Webster, 1962; J. D. Pye, Flinn \& A. Pye, 1962). In CR the ear movement is different (Schnitzler, 1970). CR which do not emit sounds keep the upper part of the pinna folded over the ear opening. When producing a single sound or a group of sounds the tip of the pinna of both ears or sometimes of only one ear is moved foreward so that the ear is fully opened in the foreward direction. Alternating movements could not be seen.

\section{DISCUSSION}

These results show a widely similar orientation behavior in both species. The question is now: what are the advantages of such an orientation system?

The upward frequency sweep at the beginning of the pulses seems to have no special meaning, for it is not changed in different orientation situations. It may be a by-product of the sound production since in RF only the first pulse of a group shows an initial frequency sweep.

The cf-part gives RF and CR the possibility to control relative movements. The frequency difference between outgoing pulse and returning echo is a measure of the relative velocity between bat and object from which the echo returns. The better the ability of RF and CR is to measure this frequency difference, the more accurate the relative velocity can be controlled. Neurophysiological studies of RF (Neuweiler, 1970) and CR (Grinnell, 1967; Henson, personal communication) show that in both species the auditory threshold of the on-answers of evoked potentials has a minimum at about the average frequency of the cf-parts of roosting bats and rises steeply at the frequencies below and above. Since flying bats lower the frequency of the emitted sounds in order to compensate for Doppler shifts and to maintain the echo frequency $100-150 \mathrm{~Hz}$ above the average frequency, the frequency of the weak returning echo is in an area where the threshold is very low. The frequency of the loud outgoing pulses is in an area where the threshold is high. Therefore the problem of masking between outgoing pulses and returning echos is diminished. This is very important for there is always an overlap within a distance of about $10 \mathrm{~m}$ in RF and $4 \mathrm{~m}$ in CR. In roosting bats there is no difference between the frequencies of emitted sounds and echos. In this situation, 
however, the bats do not have to control their own movements. If an object is moving the resulting Doppler shift compensation brings the same advantages as in flight.

The amount of Doppler shift is dependent on the cosinus of the angle between the forward direction and the direction of the returning echo. Therefore the frequencies of the echos from greater angles are lower and they fall in an area of high threshold. That means that the detection of echos from the foreward direction is favoured. This effect is increased since the sound emission at least in RF (Schnitzler, 1968) is already highly beamed.

The different echo frequency from different angles gives the bats the possibility to obtain some information on echo direction. It also diminishes the problems of masking by echos from other bats since, the case that they do not fly with the same velocity in the same direction, the frequency of the cf-part of these bats must be lower than the frequency of the own echos.

How are the bats able to keep the echo frequency constant? The results of the pendulum experiment with RF make it possible that the Doppler shift compensation is regulated in a feedback system. The bats measure the echo frequency. If it is higher than the wanted frequency, the frequency of the emitted sounds is lowered and vice versa. The situation where a flying bat emits sounds toward a moving object up to now has not been analyzed in an experiment. Therefore it is not clear whether flying bats compensate only the Doppler shifts caused by their own flight velocity or according to the relative velocity between bat and moving target.

The cf-part may also be advantageous in insect catching. The moving insect wings cause rhythmical intensity changes and, by Doppler shifts, also frequency changes. These changes might by typical for some insect species so that the bats could recognize a special prey. A long cf-part would be suitable to obtain such information.

The additional emission of the 1st and 3rd harmonic in the approach and terminal phase could be used to collect information on shape and surface of the echolocated objects. In addition to all this information the distance to an object is very important for exact localisation. The neurophysiological results of Henson (1967) make it very probable that the bats obtain the distance information by measuring the time delay between the fm-parts of pulse and echo. The auditory threshold of the off-responses in CR (Grinnell, 1967), with a minimum of about $1.3 \mathrm{kHz}$ below the minimum of the on-responses, suggests that a fm-sweep passing this frequency area could evoke a strong answer. This could be used to measure the time delay. The increase of the repetition rate in situations where exact distance information is interesting for the bats, as in the approach and terminal phase, speaks also for the importance of the fmsweep. One difference in the orientation behavior is that RF shows alternating ear movements which are more closely correlated to the sound emission than are the non alternating slower ear movements of CR. Schneider \& Möhres found that the ear movements are important for the localisation acuity. Up to now, however, there are not enough experimental results available to judge their function in the orientation system. The differences in both species make it even more difficult.

This comparison shows that a widely similar orientation system is developed in two species which are from different families and geographically separated. It would be very interesting to analyze the orientation behavior of bats in other families which produce sounds with a cf-part. Probably this would give more information as to how this complicated system works and how it was developed in evolution.

\section{REFERENCES}

Ajrapetuanz, E. Sh. \& A. I. Konstantinov, 1967. A study of nervous mechanisms of echolocation of bats. Questions of Bionics : 445-453. (Nauka, Moscow).

GriffiN, D. R., 1958. Listening in the dark. (Yale University Press, New Haven).

-, 1962. Comparative studies of the orientation sounds of bats. Zool. Soc. London, Symposium, $7: 61-72$.

Griffin, D. R., D. C. Dunning, D. A. Cahlander \& F.
A. Webster, 1962. Correlated orientation sounds and ear movements of horseshoe bats. Nature, London, 196 : $1185-1187$.

GriffiN, D. R. \& A. Novick, 1955. Acoustic orientation in neotropical bats. J. exp. Zool., $130: 251-300$.

Griffin, D. R., F. A. Webster \& R. C Michael, 1960. The echolocation of flying insects by bats. Anim. Behavior, 8 : $141-154$. 
GrinnelL, A. D., 1967. Mechanisms of overcoming interference in echolocating animals. In: R. G. BUSNEL, Animal sonar systems, 1 : 451-480. (Laboratoire de Physiologie acoustique, Jouy-en-Josas).

Henson, O. W., 1967. The perception and analysis of biosonar signals by bats. In : R. G. BuSNEL, Animals sonar systems, 2 : 949-1003. (Laboratoire de Physiologie acoustique, Jouy-en-Josas).

Kay, L. \& T. J. Pickvance, 1963. Ultrasonic emissions of the lesser horseshoe bat Rhinolophus hipposideros. Proc. zool. Soc. London, 141 : 163-172.

Konstantinov, A. I. \& B. V. Sokolov, 1969. New data on echolocation of horseshoe bats (Rhinolophidae). J. evol. Physiol. Biochem., Leningrad, 5 : 90-97.

MöHRES, F. P., 1953. Úber die Ultraschallorientierung der Hufeisennasen (Chiroptera-Rhinolophidae). Z. vergl. Physiol., 34 : 547-588.

NeUWEILER, G., 1970. Neurophysiologische Untersuchungen zum Echoortungssystem der Großen Hufeisennase Rhinolophus ferrum-equinum Schreber 1774. Z. vergl. Physiol., 67 : 273-306.

Novick, A., 1958. Orientation in palaeotropical bats, 1. Microchiroptera. J. exp. Zool., 138 : 81-154.

,- 1963a. Orientation in neotropical bats, 2. Phyllostomatidae and Desmondontidae. J. Mammal., 44: 44-56.

Novick, A. \& J. R. VAISNYs, 1964. Echolocation of flying insects by the bat Chilonycteris parnellii. Biol. Bull., $127: 478-488$.

Pye, A., 1966. The structure of the cochlea in Chiroptera, 1. Microchiroptera : Emballonuroidea and Rhinolophoidea. J. Morph., 118 : $495-510$.

,- 1967 . The structure of the cochles in Chiroptera, 3. Microchiroptera : Phyllostomatoidae. J. Morph., 121 : $241-254$.

Pye, J. D., M. Flinn \& A. Pye, 1962. Correlated orientation sounds and ear movements of horseshoe bats. Nature, London, 196 : 1186-1188.

SCHNEIDER, H. \& F. P. MöHRES, 1960. Die Ohrbewegungen der Hufeisenfledermäuse (Chiroptera, Rhinolophidae) und der Mechanismus des Bildhörens. $Z$. vergl. Physiol., 44 : $1-40$.

SCHNITZLER, H. U., 1967. Discrimination of thin wires by flying horseshoe bats (Rhinolophidae): In : $R$. G. BUSNEL, Animal Sonar Systems, 1 : 69-87. (Laboratoire de Physiologie acoustique, Jouy-en-Josas 1967).

-, 1967. Kompensation von Dopplereffekten bei Hufeisen-Fledermäusen. Naturwissenschaften, $54: 523$.

-, 1968. Die Ultraschall-Ortungslaute der Hufeisen-Fledermäuse (Chiroptera-Rhinolophidae) in verschiedenen Orientierungssituationen. Z. vergl. Physiol., 57 : 376-408.

-, 1970. Echoortung bei der Fledermaus Chilonycteris rubiginosa. Z. vergl. Physiol., 68 : 25-38. 